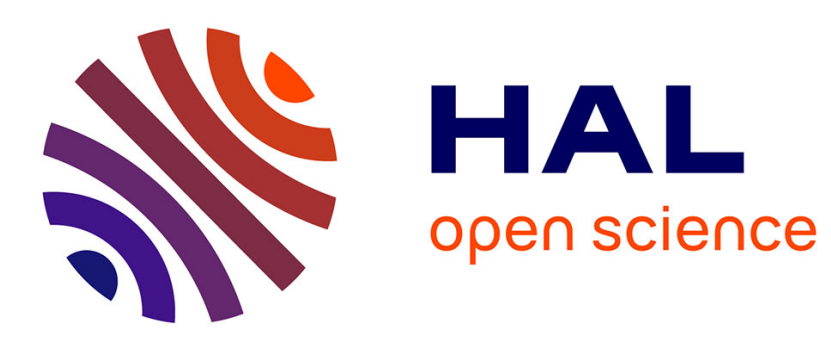

\title{
Infrared Thermography applied to transport infrastructures monitoring: outcomes and perspectives
}

Jean Dumoulin, Antoine Crinière

\section{To cite this version:}

Jean Dumoulin, Antoine Crinière. Infrared Thermography applied to transport infrastructures monitoring: outcomes and perspectives. SPIE - Thermosense: Thermal Infrared Applications XXXIX, Apr 2017, Anaheim California, United States. hal-01509555

\section{HAL Id: hal-01509555 \\ https://hal.inria.fr/hal-01509555}

Submitted on 18 Apr 2017

HAL is a multi-disciplinary open access archive for the deposit and dissemination of scientific research documents, whether they are published or not. The documents may come from teaching and research institutions in France or abroad, or from public or private research centers.
L'archive ouverte pluridisciplinaire HAL, est destinée au dépôt et à la diffusion de documents scientifiques de niveau recherche, publiés ou non, émanant des établissements d'enseignement et de recherche français ou étrangers, des laboratoires publics ou privés. 


\title{
Infrared Thermography applied to transport infrastructures monitoring: outcomes and perspectives
}

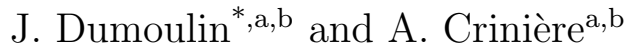 \\ aFSTTAR, COSYS-SII, Route de Bouaye - CS4, F-44344, Bouguenais, France \\ bInria, I4S Team, Campus de Beaulieu, F-35042 Rennes, France
}

\begin{abstract}
Long term monitoring of transport infrastructures by infrared thermography has been studied and tested on different structures. A first standalone infrared system architecture developed is presented and discussed. Results obtained with such system on different Civil Engineering structures are presented. Some data processing approaches and inverse thermal model for data analysis are introduced and discussed. Lessons learned from experiments carried out in outdoor with such system are listed and analyzed. Then, a new generation of infrared system architecture is proposed. Finally, conclusions and perspectives are addressed.
\end{abstract}

Keywords: Infrared thermography, Long term monitoring, Thermal model, Civil engineering, SHM systems

\section{INTRODUCTION}

Being able to perform full field easily noninvasive diagnostics for surveillance and monitoring of transport infrastructures and structures is a major preoccupation of many technical offices. Among all the existing electromagnetic methods, long-term thermal monitoring by uncooled infrared cameras is a promising technique. In situ measurements by infrared thermography on large scale structures in outdoor conditions will be introduced and constraints will be analyzed versus technological solutions available on the shelf.

This paper introduce the concept developed in the past years for outdoor deployment of infrared thermal systems on real structures. First, evolution of the long term thermal monitoring systems developed is presented. Then four study are detailed, from the civil engineering structure long term monitoring to building thermal survey strategy. For each study data acquired are presented and discussed, and results obtained with data analysis procedure using various techniques like Fourier analysis or inverse thermal model are detailed. Finally conclusions are drawn and discussions on the future of such approach is open.

\section{INFRARED THERMOGRAPHY SYSTEM DESIGNED FOR OUTDOOR APPLICATIONS}

We introduce in this section the concept developed in the past years for outdoor deployment of infrared thermal systems on real structures. For many years now our research team aim at developing systems able to manage infrared thermal cameras synchronized with other sensors (for instance environmental ones). A first system called IrLaW have been developed, ${ }^{1}$ built for in-labs experiment ${ }^{2}$ and based on a legacy Ubuntu. Inherited from its main specification IrLaW is able to define physicals and data models and can fully take advantage of GPU technologies ${ }^{3}$ to live compute them. ${ }^{4}$ The growing needs of aging civil engineering structure maintenance have encouraged us to propose an upgrade of the system able to collect infrared and environmental data on-site, see figure 1.

The IRLaW architecture, with extended functionalities (toward IoT), was developed among the FP7 project ISTIMES $^{5}$ and were designed to inter-operate within a wide ICT architecture based on the OGC requirements. ${ }^{6}$ This action lead to numerous studies from day to day infrared monitoring ${ }^{7}$ to model calibration for temperature measurement ${ }^{8}$ which results will be drawn on this study, sections 3 and 4 . By definition, naturals thermals phenomenons that occurs in wide concrete structures are quite slow, in order to provide results throughout all the structure life it have been decided to use that system over more than a year. ${ }^{9}$

\footnotetext{
*jean.dumoulin@ifsttar.fr; phone 332 4084-5624; fax 332 4084-5998; www.ifsttar.fr
} 


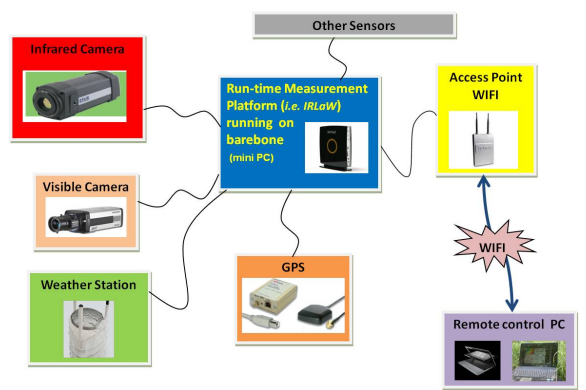

Figure 1: IrLaW former architecture.
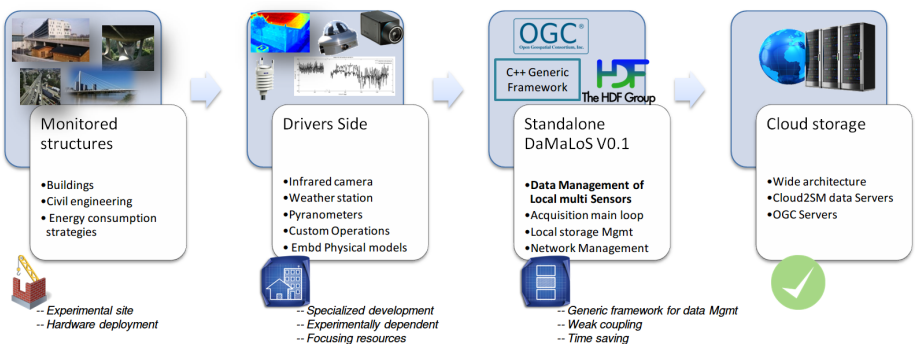

Figure 2: Cloud2IR ongoing architecture.

Within this first long term attempt we faced various management issues (sensors life, data coherency etc...), based on those statements the Cloud2SM project ${ }^{10}$ have been launch in 2015 to provide a system dedicated to long term infrared monitoring. This new action was based on the need of modularity of such system. Four main ideas have driven the development, take advantage of the IrLaw legacy, no HMI (Human Machine Interface) needed, provide a generic development framework to adapt effortlessly to each experiment specificities and insure the data standardization. Based on those specifications Cloud2IR ${ }^{11}$ software have been developed, see figure 2 .

The modularity of the system is the key to adaptation so Cloud2IR has been developed in order to cut down software integration time which facilitates the system configuration to each experiment specificity. Designed to be used in a distributed architecture providing computing clusters and cloud storage, the system is based on two main principles, first the sensors/experiment side ( left blocks in figure 2) which are hardware dependent and can be molded to fit the experimental reality, then a data side ( right blocks in figure 2) weakly coupled with the sensor side and consisting in a general framework able to aggregate any sensor data, type or size and automatically encapsulate them in various generic data format as HDF5 or OGC SWE standard and endowed of networking capability. ${ }^{6,12}$ Results of first years of measurements with Cloud2IR using FLIR AX5 ${ }^{13}$ next gen infrared cameras are presented section 5 .

\section{USING MEASURED ENVIRONMENTAL PARAMETERS FOR MEASUREMENT CORRECTIONS: EXAMPLE OF TEST CASE BRIDGE IN SWITZERLAND}

This section introduce some results of a former study ${ }^{8}$ proposed to demonstrate assets of IR imaging in foggy conditions and days monitoring on highway structure. The whole measurement system was implemented (in May 2011) in the Sihlhochstrasse viaduct, located in Zurich (Switzerland). No traffic interruption was required during the mounting and dismantling of measurement system. Figure 3 shows an overview of the Sihlhochstrasse bridge and the location of the arch concerned by the installation of the uncooled infrared system.

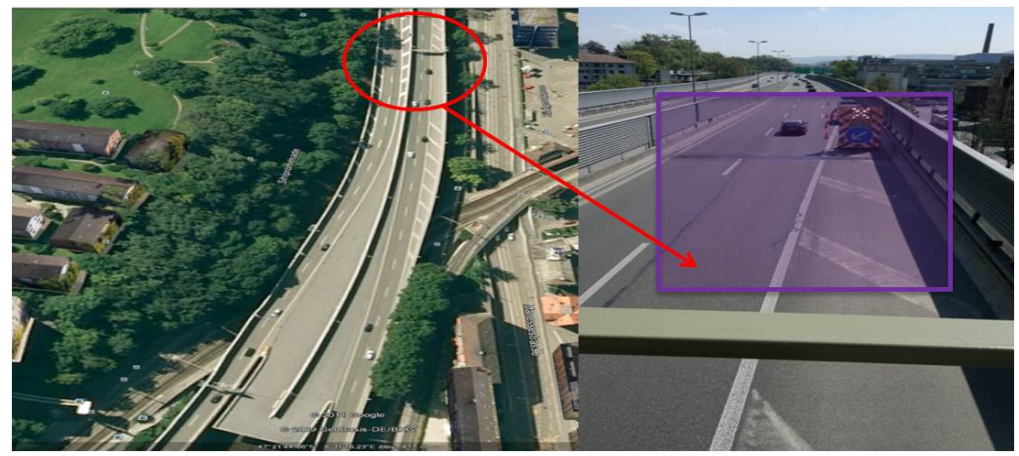

Figure 3: Sihlhochstrasse viaduct 
Infrared thermography used for accurate thermal measurements requires to process in real time radiative corrections to take into account environment evolution with time. This have been done here using GPU technology ${ }^{3}$ and a simplified radiometric heat balance, ${ }^{1415}$ (figure 4 and equation 1), with a given atmospheric transmission. ${ }^{16}$

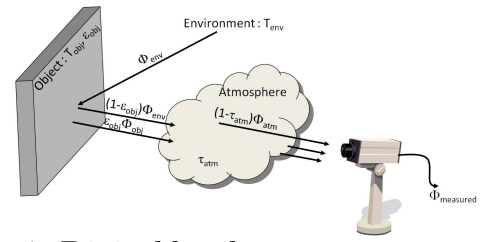

$$
D L=\tau_{a t m} \epsilon_{0} D L_{0}+\tau_{a t m}\left(1-\epsilon_{0}\right) D L_{e}+\left(1-\tau_{a t m}\right) D L_{a t m}
$$

Figure 4: Digital levels to temperature model

Where $\tau_{a t m}$ the atmospheric transmission computed, $\epsilon_{0}$ the measured object emissivity and $D L$ the global received radiative heat flux converted in digital level at detector outlet level. $D L_{0}$ matches the radiative contribution from the object, $D L_{e}$ and $D L_{a t m}$ match the respective contribution of the environment and the atmosphere assumed to behave like grey body at an equivalent known temperature. The long term monitoring test last 2 days and an half. During these trials infrared digital level, outside temp and Relative Humidity were stored. Thermal images were acquired at a frame rate of $0.1 \mathrm{~Hz}$ by averaging 50 thermal images with an initial camera frame rate fixed at $5 \mathrm{~Hz}$ using a FLIR A320 IR camera. Each hour, a thermal image sequence was stored on the internal hard drive of our system and data were also retrieved, on demand, by using wireless connection with a notebook. First in addition of a distance matrix, previous transmission law is computed, figure 5 .

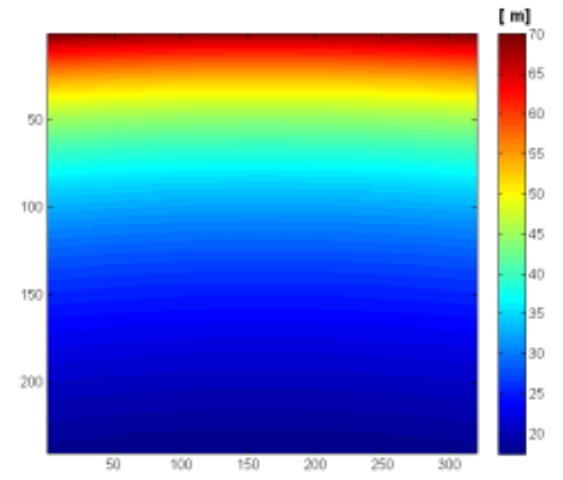

(a)

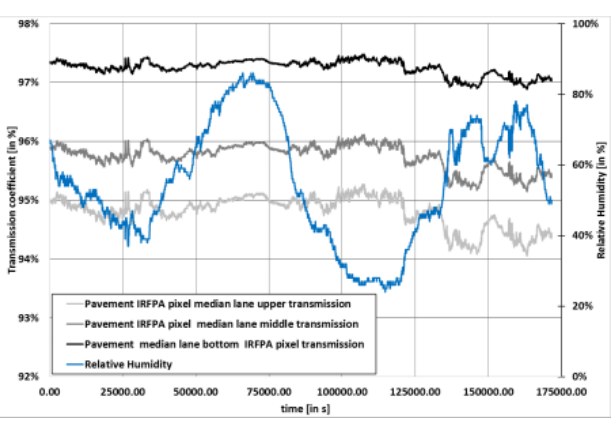

(b)

Figure 5: Distance matrix (a), transmission computation (b)

Which allow us to compute in real time the temperature evolution over the bridge deck following manufacturer model, figure 6 .
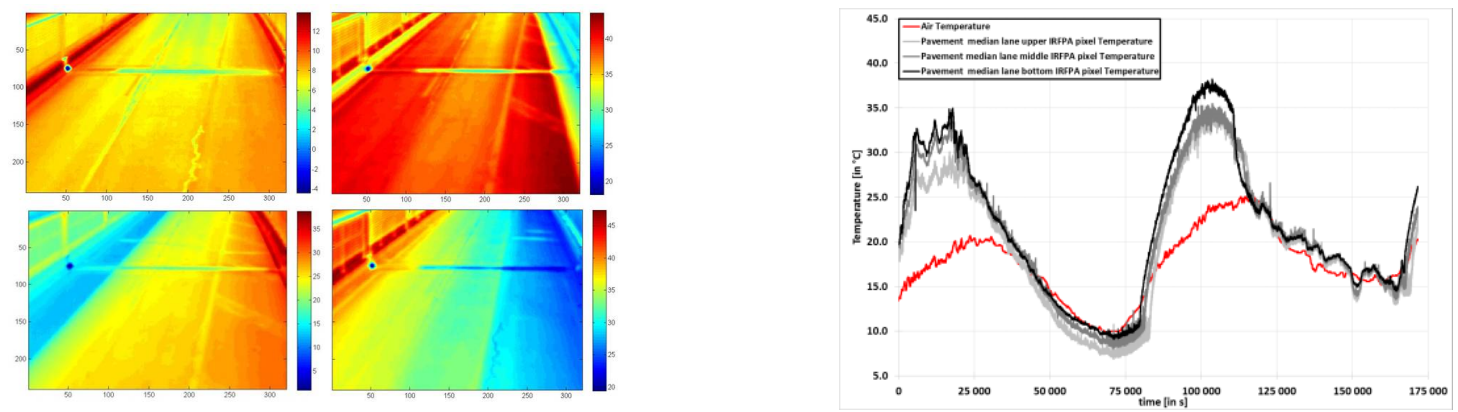

Figure 6: Measured temperature on viaduct surface 
During these experiments the sun course was perpendicular to the main direction of the bridge. Such situation induces a transversal thermal gradient at deck level for a finite period duration while thermal loading (morning) and relaxation (end of afternoon and evening). In figure 6 left it can be observed the distribution of the transversal temperature gradient occurring during the thermal load and relaxation associated to solar heat flux and the sun position versus the bridge deck. The average method proposed for data acquisition (leaving the thermal infrared camera running at a high frequency and storing the average data each $10 \mathrm{~s}$ ) seems to be efficient to follow the effect of environmental change on to surface temperature that match thermal local equilibrium at different periods of the day (i.e. effect of object local thermal inertia). Moreover such method appear efficient to lower the impact of the traffic on the measurement.

A Fourier analysis ${ }^{17}$ was applied to temporal evolution of each pixel of the thermal image. The magnitude and phase maps were analyzed to detect constitutive elements in the inner structure of the bridge deck, figure 7 .

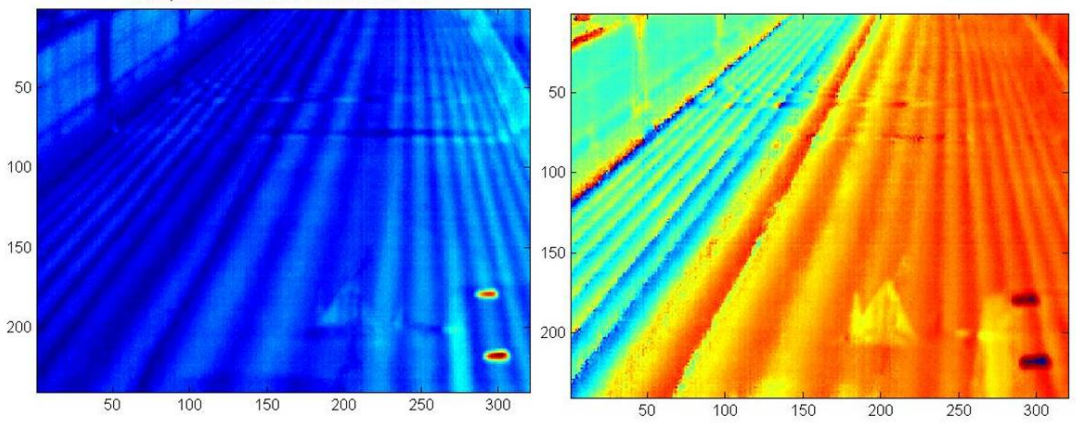

Figure 7: Amplitude and phase maps

The inner structure of the bridge deck could be observed on both images. In particular, post tensioned transversal tendons could be detected in the upper part of the maps around $n^{\circ} 50$ pixel (supposed to be located in the upper part of the concrete deck under the asphalt wearing course). For longitudinal post tensioned duct complementary analysis should be required. Nevertheless, the phase map seems more affected by the presence of some security signal on the deck during lane closing due to temporary access to the arch for other different measurements realized during this trial.

\section{DATA ANALYSIS AND INVERSE THERMAL MODELING IN AN SHM APPROACH :EXAMPLE OF TEST CASE BRIDGE IN ITALY}

This former study ${ }^{7}$ propose to validate the process seen previously combined to an inverse thermal modeling procedure. The Musmeci bridge, shown in figure 8, is located in Potenza (Italy). It is made up of a reinforced concrete box plank, held each $17.30 \mathrm{~m}$ by a reinforced concrete continuous vault equivalent to four arches with wheelbases of $17.30 \mathrm{~m} 4=69.20 \mathrm{~m}$ and a free span amongst the supports of $58.80 \mathrm{~m}$.

The entire bridge consists of four spans of $69.20 \mathrm{~m}$ with an overall length of $277 \mathrm{~m}$ and is known to be an example of static load optimization of concrete structures. ${ }^{18}$ The whole measurement consist on an FLIR A320 infrared camera coupled with a VAISALA WXT520 weather station, and a UBLOX GPS unit for positioning and timing. The system was implemented on the Musmeci bridge in July 2011. No traffic interruption was required during the mounting of our measurement system. To assess temperature measurement, the same strategy as presented in section 3 have been achieved. This trial took place over three days, thermal images were acquired at a frame rate of $0.1 \mathrm{~Hz}$ by averaging 50 thermal images with an initial camera frame rate fixed at $5 \mathrm{~Hz}$. The figure 9 show thermal images at different times of the daynight cycle under natural thermal solicitation as well as environmental data acquired during the experiment.

As the bridge deck is oriented $\mathrm{S} / \mathrm{E}-\mathrm{N} / \mathrm{O}$ it is not located exactly in the solar axis, thus the body guard of the shadow appears on these thermal images. Note that the internal structure of the bridge is detectable during the thermal relaxation, this observation indicates that the information on the internal structure is contained in the 

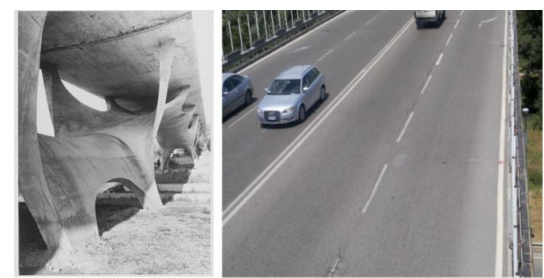

Lato Basentana

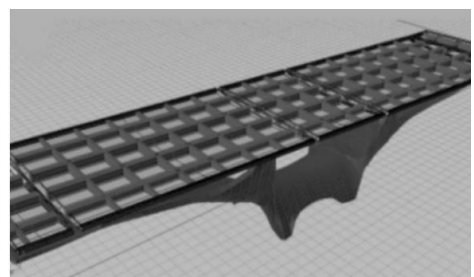

Lato Potenza

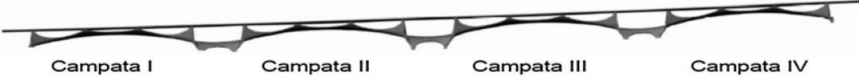

Figure 8: The Musmeci bridge in Potenza - Italy

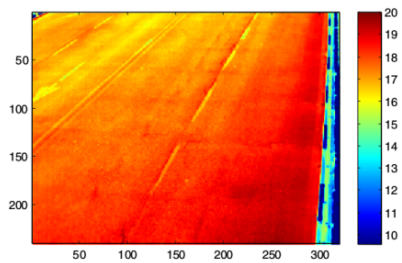

End of thermal relaxation

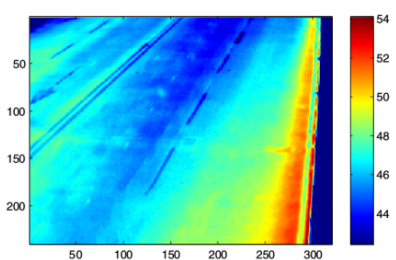

End of temperature raising

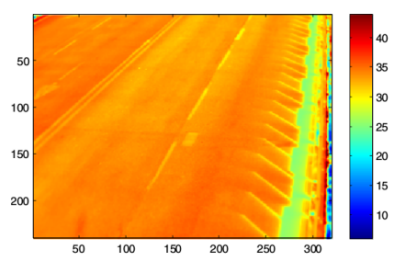

During thermal loading

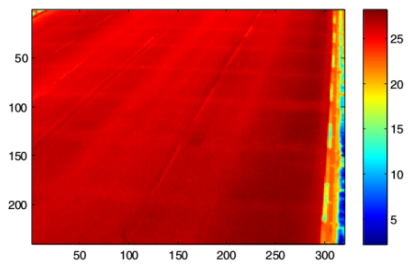

During thermal relaxation
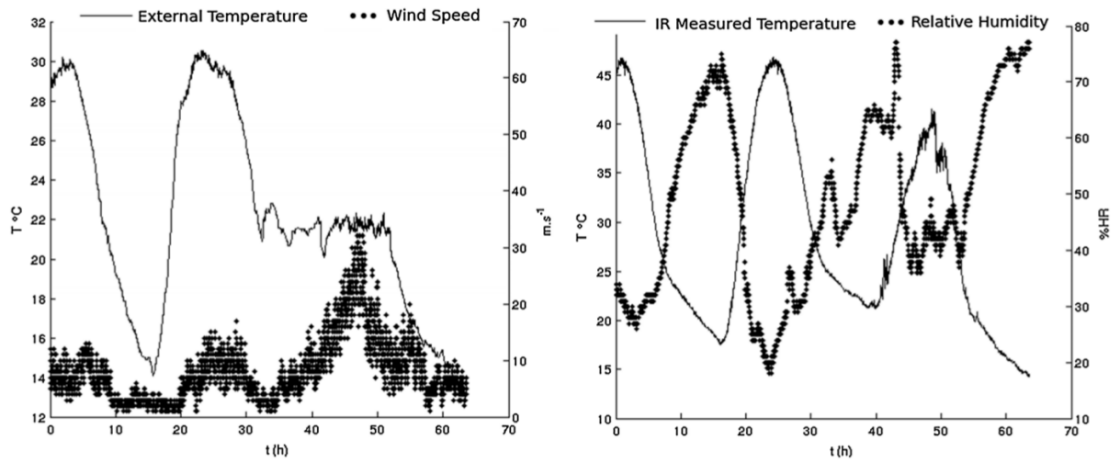

Figure 9: Data acquired during the experiment

thermal images measured. So it appears that a parameter estimation procedure could give us some interesting results. On the third day a non-negligible raising of the wind speed (up to $100 \mathrm{Km} . \mathrm{h}^{-1}$ ) can be observed, with a quasi-constant external temperature in parallel. The measured relative humidity shows a burst of humidity during the third day in particular. It matches the sudden wind event but also random sun shadowing by clouds and the external temperature stabilization. A combination of the convective effect and external temperature reduce the thermal relaxation during night time on the beginning of the third day. If we focus the analysis on the first two days, the measured data have a periodic behaviour with a status close to the pseudo permanent regime. The complex amplitude method ${ }^{19}$ can be used to express a thermal model of the bridge deck. The system is expressed in equation 2, moreover, considering that the deck has a large thickness, its nature and the fact that we only look at a few daily periodic thermal perturbations at the deck surface, an adiabatic boundary condition was applied on the rear face of the deck.

$$
\begin{cases}j \omega b^{2} \tilde{T} & =\partial_{x^{*}}^{2} \tilde{T}\left(\omega_{n}\right) \\ \left.\partial_{x^{*}} \tilde{T}\left(\omega_{n}\right)\right|_{x^{*}=0} & =\tilde{\varphi}\left(\omega_{n}\right) \\ \left.\partial_{x^{*}} \tilde{T}\left(\omega_{n}\right)\right|_{x^{*}=\infty} & =0\end{cases}
$$


Where $x^{*}$ is the space variable expressed in term of resistivity $x^{*}=x / k$ in $W m^{-1} K^{-1}$ with $k$ the thermal conductivity, $b$ the thermal effusivity in $W s^{1 / 2} m^{-2} K^{-1}$ and $\omega_{n}=2 \pi f$ the pulsation. The model is solved thanks to the thermal quadrupoles method, ${ }^{20}$ expressed here for a single-layer material, equation 3 :

$$
\begin{aligned}
\left(\begin{array}{c}
\left.\tilde{T}\left(\omega_{n}\right)\right|_{x^{*}=0} \\
\left.\tilde{\varphi}\left(\omega_{n}\right)\right|_{x^{*}=0}
\end{array}\right) & =\left(\begin{array}{cc}
\cosh \sqrt{j \omega_{n}} b R & \left(b \sqrt{j \omega_{n}}\right)^{-1} \sinh \sqrt{j \omega_{n}} b R \\
b \sqrt{j \omega_{n}} \sinh \sqrt{j \omega_{n}} b R & \cosh \sqrt{j \omega_{n}} b R
\end{array}\right)\left(\begin{array}{c}
\left.\tilde{T}\left(\omega_{n}\right)\right|_{x^{*}=\infty} \\
0
\end{array}\right) \\
& =\left(\begin{array}{cc}
A\left(\omega_{n}\right) & B\left(\omega_{n}\right) \\
C\left(\omega_{n}\right) & D\left(\omega_{n}\right)
\end{array}\right)\left(\begin{array}{c}
\left.\tilde{T}\left(\omega_{n}\right)\right|_{x^{*}=\infty} \\
0
\end{array}\right)
\end{aligned}
$$

Return in time domain is carried out with the discrete Fourier inverse transform ${ }^{17}$ computed on the model solution to express the time-dependant temperature:

$$
T(0, t)-T_{m}=\left.\frac{1}{N} \sum_{n=0}^{N} \frac{A\left(\omega_{n}\right)}{C\left(\omega_{n}\right)} \tilde{\varphi}\left(\omega_{n}\right)\right|_{x^{*}=0} \exp ^{2 j \pi t \frac{n}{N}}
$$

In order to lower the amount of data and optimize the computation time, the most regular daily period has been chosen and sub-sampled to $0.0083 \mathrm{~Hz}$. As the solar heat flux wasnt measured during the trial we have to compute it. The global heat flux density computation is based on the identification of the convective flux and the solar heat flux at the bridge deck surface, equation 5 .

$$
\varphi(t)=h(t)\left(T_{e x t}-T_{\text {deck }}\right)+\varphi_{0}(t)
$$

A convective heat transfer coefficient, $h(t)$, is computed for each wind speed thanks to the McAdams correlation. ${ }^{21}$ Furthermore, the bridge deck is subjected to a variable solar heat flux, reconstructed here by the Duffie and Beckman solar heat flux model ${ }^{22}$ has been used. The figure 10 (left) show the reconstruction convective heat transfer coefficient achieved thanks to filtrated environmental data, while figure 10 (right) present the reconstruction of $\varphi(t)$.
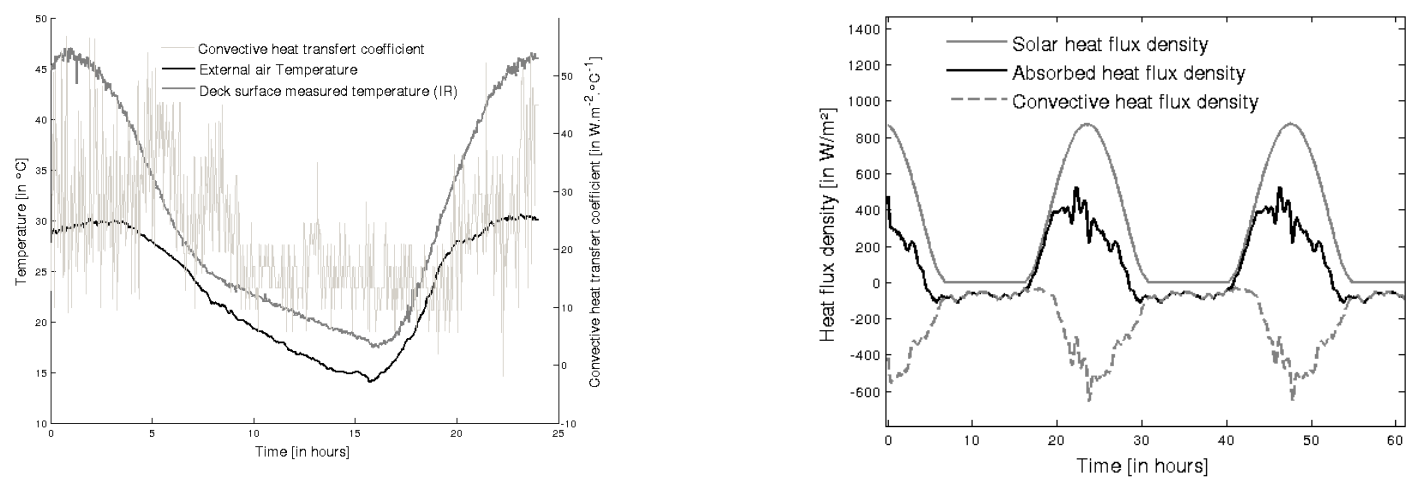

Figure 10: Convective heat transfer and solar heat flux reconstruction

Now, as the inputs $\varphi$ and $h$ of the model are reconstructed they can be injected in the equation 4 . For this study the apparent thermal effusivity estimation is carried out by a custom GPU ${ }^{23}$ version of the the non-linear least square Levenberg Marquardt algorithm ${ }^{24}$ built within Matlab software, as the model is solved in a frequency domain, GPU optimized FFT and inverse FFT are also used. A spatial mean have been done to reduce the data to a 100x120px sequence. The non optimized version of the estimation procedure had a $70 \mathrm{~h}$ computational cost. The first GPGPU * implementation, slightly improved, has done the same job within $3 \mathrm{~h}$. In order to compare and validate result an FFT has been compute on the same sequence, figure 11.

*NVIDIA GT 555M 


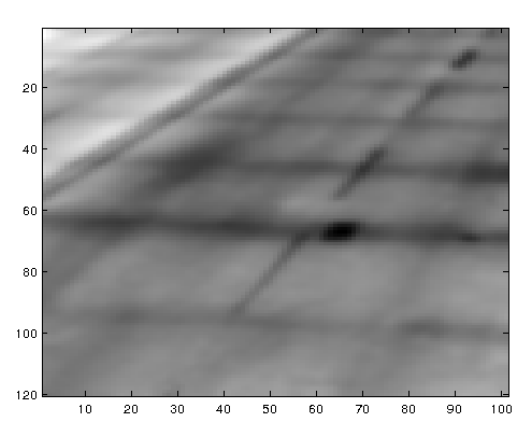

(a)

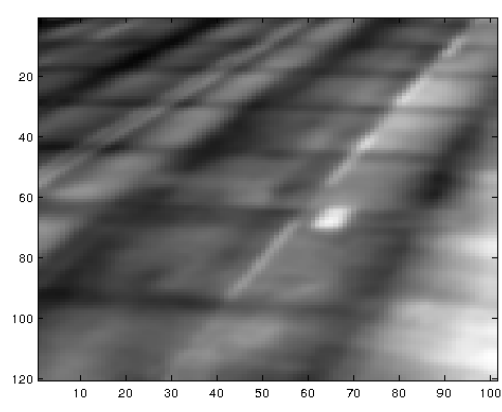

(b)

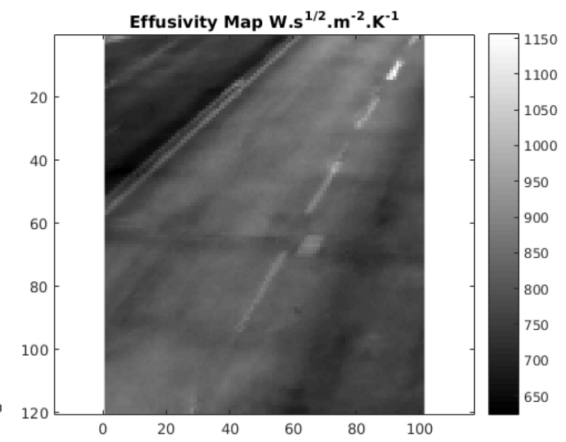

(c)

Figure 11: Comparison between FFT amplitude map (a), phase map (b) and model computation (c)

Comparing the FFT phase map to the effusivity map show that the estimation procedure, is able to detect and characterize any apparent variation in the properties of the deck structure; indeed the first caisson can be seen. It could also be seen that the traffic appear to reinforce the vertical beam. However the surface condition of the structure, the shadow, the spatial distortion due to the field of view of the camera and the emissivity approximation within the temperature conversion affect the model results. Other ways of optimization could be investigated, like solving the minimization algorithm in frequency domain or express $\varphi(t)$ directly with the model and apply a circular estimation algorithm in order to avoid the measure injection on the model, otherwise the measure of the solar heat flux density appear mandatory.

\section{EXTENDING THE SYSTEM TO BUILDING THERMAL SURVEY}

Building thermal survey for energy saving is a growing problem among ecological international engagement (as the COP21), the following study present the use of a thermal monitoring system to assess thermal survey as well as building monitoring. ${ }^{11}$

\subsection{SenseCity test bed}

Sense-City, ${ }^{25}$ figure 12 is a large scale equipment which has received support from the French government in the framework of the Programme d'Investissement d'Avenir ${ }^{\dagger}$.

This project is led by the French Institute of Science and Technology for Transport, Development and Networks (IFSTTAR) with ESIEE- Paris, the Laboratory of Physics of Interfaces and Thin Films (LPICM) and the Scientific and Technical Centre for Building (CSTB) as consortium partners. The Sense-City project is a suite of high-quality facilities for the design, the prototyping and the evaluation of performance and risks of innovative micro and nanotechnology based sensors devoted to measurements in urban environment which will be fully operational in 2017. While waiting the full site availability a first demonstrator have been built at the IFSTTAR headquarter office. This first site is fully instrumented (smart road, energy consumption efficiency, GPR test site...) and this is where our long term infrared monitoring system has been deployed since almost three years now. The IT system is deployed on a zotac mini PC under ubuntu. Composed of an IR camera FLIR AX5 ${ }^{13}$ a weather station, a pyranometer and a GPS, the system is designed to operate on normal or emergency power supply. The figure 13 shows samples of thermal imaging acquired the 13 march 2016 by the system over day-night cycle in Digital level.

Its interesting to see the sun path influence, especially on sunrise where only the main side of the lodge is heated and where it can be seen the shadow of the second lodge. In the figure 13, at sunset and during the night, the effects of the local atmosphere inside the lodge are clearly visible and roof superstructure can be discriminated, during the night the presence of an insulating material can be clearly discriminated.

In figure 14 we present the time evolution (each 60s) of four typical pixels over a week and also the air temperature and solar heat flux evolution synchronized measurements during this period.

\footnotetext{
${ }^{\dagger}$ Future Investment Programme
} 


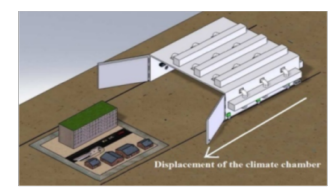

(a)

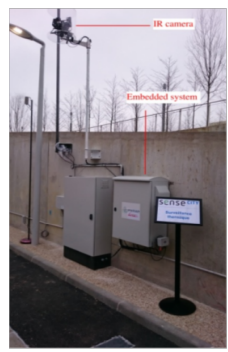

(c)

(d)

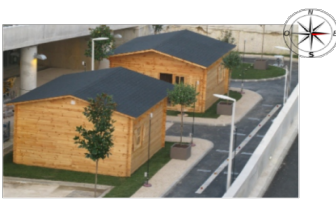

(b)

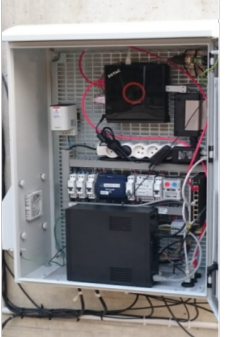

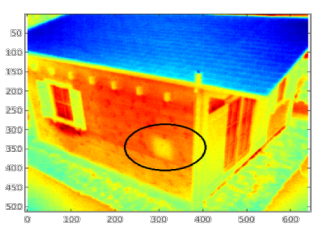

(e)

Figure 12: Future Sense-city test site (a) actual first demonstrator (b) deployed system (c) hardware system (d) thermal image acquired at sunrise (e).
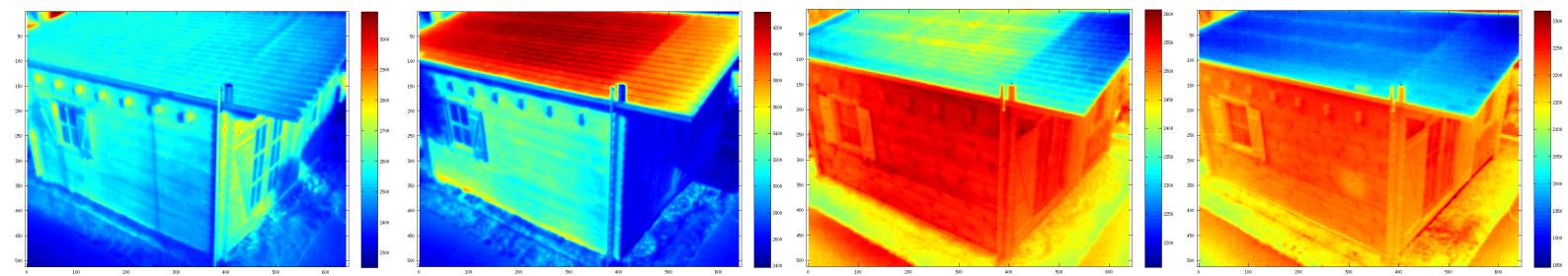

Figure 13: IR images acquired 13rd march 2016 around, sunrise, noon, sunset and during the night
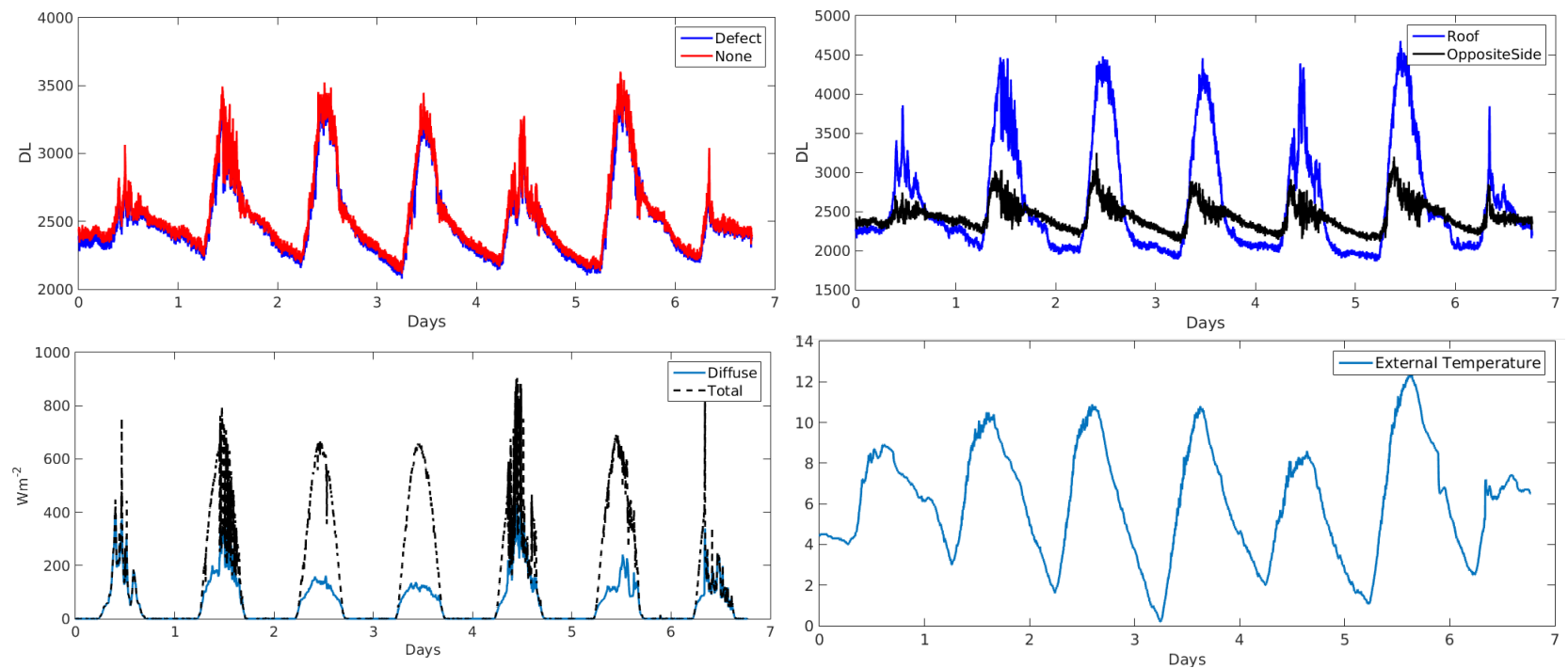

Figure 14: Evolution of various pixels digital levels, solar heat flux and external temperature from the 10 to the 16 march 2016.

The four pixel are respectively located on the front wall (left wall with a windows on the thermal image), on the insulating defect (visible on figure 13), on the roof and on the opposite side of the lodge. Over this seven days it appears that the insulating flaw have a slight effect (above the ambient noise) mainly visible on the relaxation phases, especially when the weather seems cloudy. The lodge is east oriented so the opposite 
side is sunbathed once a day at sunrise and during few hours, whereupon it enter in relaxation phase, it will certainly be interesting to induce another insulating defect on this side. The roof shows a stronger behavior, its solar orientation as its apparent emissivity and the fact that the inner roof is thermally insulated can induce such attitude. Like on the previous study a Fourier analysis ${ }^{17}$ have been done on the acquired data, for such analysis as the phenomenon is slow we increase the sampling time up to 10 minutes, the figure 15 present the amplitude and phase map for an harmonic frequency equivalent to a 60 hours time period.
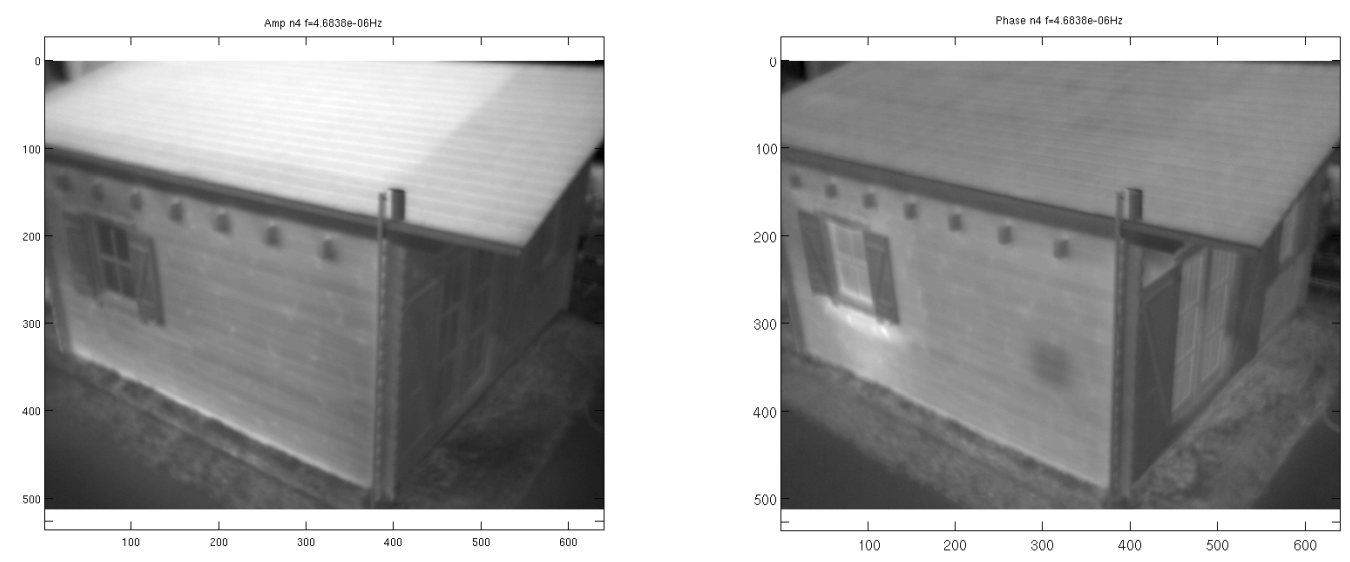

Figure 15: Amplitude and phase map compute on march data

On the amplitude map the effects of the local atmosphere inside the lodge are clearly visible but on this selected harmonic the lodge superstructure is not detected. The presence of an insulating material, in accordance with the theory, produce a phase shift on the data which can be discriminated on the phase map. Another interesting point is that the heater located inside the loge below the window also produce a phase shift, once again it's not clearly visible in the amplitude map but its presence is detected in the phase map the lodge wall (see below window on the left).

\subsection{Inria test bed}

A second test site have been instrumented in the Inria office of Rennes France. This test bed differ from SenseCity as the building, currently in use, present various facade natures with different orientation and composed of multimaterials, see figure 16 . Those particularities make this test bed unique and promising for future experiments. For now the site is composed of just an uncooled IR camera FLIR AX $5^{13}$ and run since the beginning of 2016 .
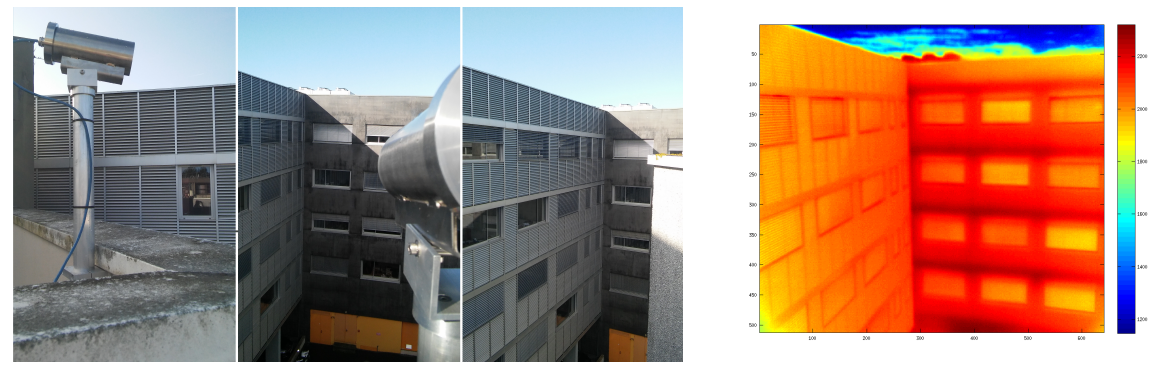

Figure 16: Inria test bed, and main IR image around sunrise.

The figure 17 show multiple digital level maps acquired during the 24 January 2016. Unlike the figure 16 those maps have been cropped in order to focus on the Inria buildings. By comparison with the SenseCity test bed, it can be seen that the inner structure of the building seems to appears on IR data during the night but without treatment it does not clearly appear at sunset for example, also data on the left building appears hard to interpret which highlight the multi-material specificity of such test bed. 

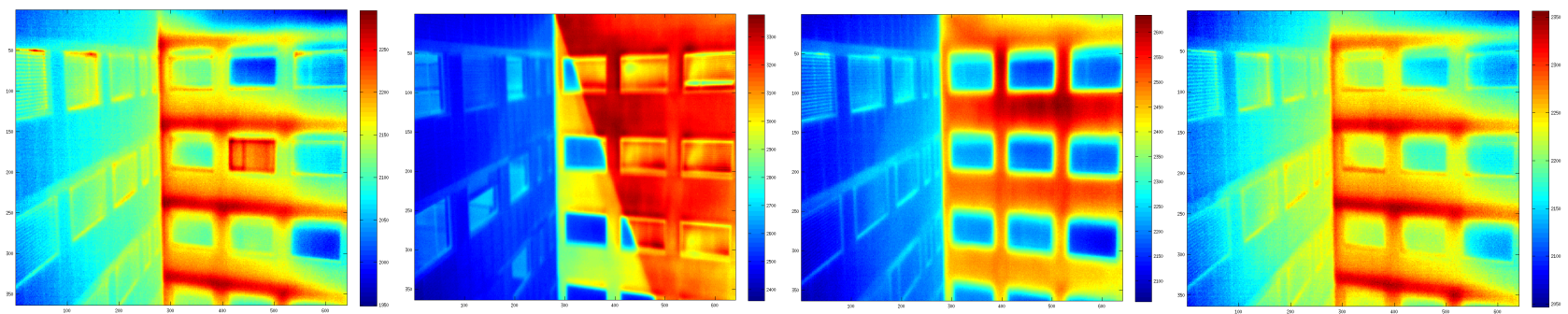

Figure 17: Digital levels acquired the 25 February 2016, sunrise, noon, sunset and during the night.

As the buildings orientation are N/E ans S/E it's interesting to see on figure 17 the impact of the sun path when the sun start to goes down. The figure 18 shows the evolution of two pixels belongings to each buildings. Both pixels are East oriented so they are sunbathed at least in the morning, but (as for the lodges on the senseCity test site) the buildings oriented north east have a smaller solar contribution the rest of the day. Another point is that the third and fourth day, the S-E buildings thermal evolution is affected by wind gust (increase of lost by convective effects), so thermal amplitude is lower.
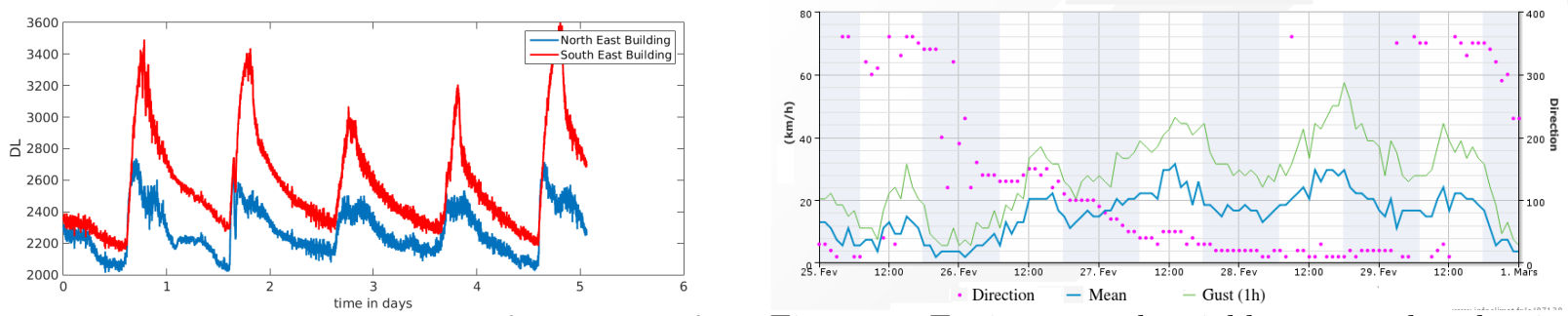

Figure 18: Digital levels evolution of two pixels from Figure 19: Environmental variable measured at the airthe 25 to the 29 February 2016. port around the same dates.

The figure 19 present some environmental variable measured at the Rennes airport (about 10Km from the test site), Theses data have been obtained thanks to www.infoclimat.fr. By looking the 27 and 28 February, the wind speed increase and the wind orientation is about zero degrees ( 0 and 360 correspond to the North) and does not change for a while, by crossing the available data it appear that the south east oriented building face a strong wind the 27 and 28 February affecting its surface thermal amplitude. Complementary instrumentation will be installed on this second test site, in order to develop quantitative analysis. As for the other study a Fourier analysis ${ }^{17}$ is also proposed here on subsampled data, the figure 20 only present phase map for two harmonic frequency equivalent to a 90 hours and 24 hours time period.
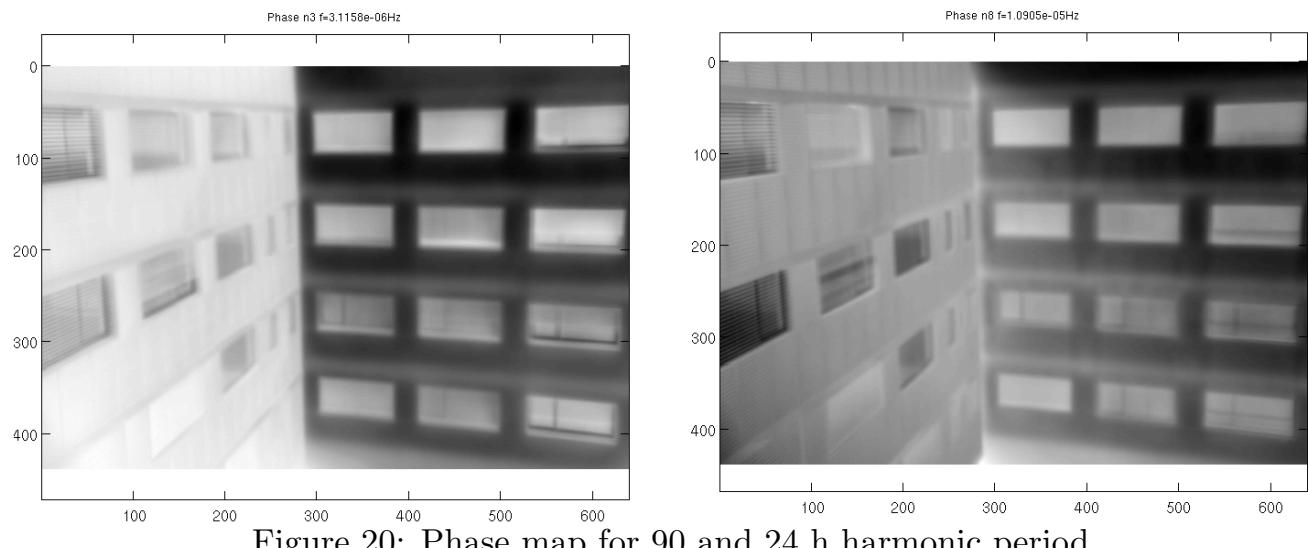

Figure 20: Phase map for 90 and $24 \mathrm{~h}$ harmonic period 
Once again flooring of the second building can be discriminated, those are well known to be thermal bridges. The phase map corresponding to a daily periodic harmonic appear more precise. Amplitude maps are not presented here due to the complexity of the building and their difficile analysis. Another particularity of such building is the presence of glass material which can induce false analysis regarding to the infrared camera acquisition wavelength.

\section{CONCLUSION AND PERSPECTIVES}

This paper have introduced a concept developed in the past years for outdoor deployment of infrared thermal systems on real structures. First evolution of the long term thermal monitoring systems developed leading to an autonomous modular and generic software is presented. Then various studies presenting our measurement approach are detailed, from temperature correction and thermal modeling for structural monitoring to building thermal survey. Among those experiments we show the capacity of infrared measurement and imaging to assess the long term infrared monitoring of civil engineering structures and provide quantitative informations to stakeholders. In addition to various Fourier analysis, an inverse thermal model have also be used in order to characterize apparent properties of a bridge deck, although this approach appears affected by various phenomenons, results obtained are encouraging for the design of future quantitative analysis methods. Last but not least, our new developed measurement system architecture has shown the assets of modularity. Few complementary developments are planned to be in full accordance with data standards and integrated on a wide distributed architecture.

\section{ACKNOWLEDGMENTS}

The authors wish to thank Rodolphe Averty for his past contribution to the IrLaW development, as well as the European project FP7 ISTIMES and the SenseCity French "Investissement d'Avenir (PIA)" project for their financial support.

\section{REFERENCES}

[1] Dumoulin, J. and Averty, R., "Infrared imaging system monitors transportation structures in real time," Spie Newsroom 10 (2014).

[2] Criniere, A., Dumoulin, J., Ibarra-Castanedo, C., and Maldague, X., "Inverse model for defect characterisation of externally glued cfrp on reinforced concrete structures: comparative study of square pulsed and pulsed thermography," Quantitative InfraRed Thermography Journal 11(1), 84-114 (2014).

[3] NVIDIA, "Cuda c programming guide," tech. rep., NVIDIA (2017).

[4] Dumoulin, J. and Averty, R., "Development of an infrared system coupled with a weather station for real time atmospheric corrections using gpu computing: Application to bridge monitoring," in [11th International Conference on Quantitative InfraRed Thermography], (2012).

[5] Proto, M. et al., "Transport infrastructure surveillance and monitoring by electromagnetic sensing: the istimes project.," Sensors 10 (2010).

[6] OGC, "Sensor web enablement: Overview and high level architecture," White Paper 07-165r1, Open Geospatial Consortium (2013).

[7] Dumoulin, J., Criniere, A., and Averty, R., "The detection and thermal characterization of the inner structure of the musmeci bridge deck by infrared thermography monitoring.," Journal of Geophysics and Engineering 10 (2013).

[8] Dumoulin, J. and Boucher, V., "Infrared thermography system for transport infrastructures survey with inline local atmospheric parameter measurements and offline model for radiation attenuation evaluation," Journal of Applied Remote Sensing (2014).

[9] Crinière, A., Dumoulin, J., Bourquin, F., and Perez, L., "Civil engineering structure daily monitored through IR Thermography and environmental measurement," in [12th International Conference on Quantitative InfraRed Thermography], (July 2014).

[10] Criniere, A., Dumoulin, J., Mevel, L., Andrade-Barosso, G., and Simonin, M., "The cloud2sm project," in [European Geosciences Union General Assembly], (2015). 
[11] Crinière, A., Dumoulin, J., Mevel, L., and Andrade Barroso, G., "Cloud2IR an infrared and environmental SHM information system," in [13th Quantitative Infrared Thermography Conference QIRT2016], 13th Quantitative Infrared Thermography Conference QIRT2016 (July 2016).

[12] Delin, K. A., "Sensor webs in the wild," Wireless Sensor Networks: A Systems Perspective. Artech House. (2005)

[13] FLIR, "Genicam icd flir ax5 camera - pc," Tech. Rep. T 559 775, Rev. C, FLIR Systems AB (2013).

[14] Gaussorgues, G., [La thermographie infrarouge: Principes, Technologies, Applications], Lavoisier (1989).

[15] Howell, J. R. and Siegel, R., [Thermal radiation heat transfer], CRC Press, Boca Raton, fifth ed. (2010).

[16] Shettle, P. and Fenn, R. W., "Models for the aerosols of the lower atmosphere and the effects of humidity variations on their optical properties report 79-0214," tech. rep., Air Force Geophysics Laboratory (1979).

[17] Rao, K. R., Kim, D. N., and Hwang, J.-J., [Fast Fourier Transform - Algorithms and Applications], Springer Publishing Company, Incorporated, 1st ed. (2010).

[18] Capomolla, R., "Il ponte sul basento di sergio musmeci. il progetto della forma strutturale prima dellavvento del calcolo automatico," Atti del Primo Convegno Nazionale di Storia dellIngegneria (2006).

[19] Carslaw, H. S. and Jaeger, J. C., [Conduction of heat in solids], Oxford : Clarendon Press (1959).

[20] Maillet, D. et al., [Thermal Quadrupols - Solving the heat equation through integral transforms], WILEY (2000).

[21] McAdams, W., [Heat Tranmission], McGraw-Hill, New York (1954).

[22] Duffie, J. and Beckman, W., [Solar engineering of thermal process], John Wiley And Sons (1991).

[23] David B. Kirk and Wen-mei W. Hwu, [Programming Massively Parallel Processors A Hands-on Approach], Elsevier (2010).

[24] Levenberg, K., "A method for the solution of certain non-linear problems in least-squares.," Quart. Appl. Math (1944).

[25] Derkx, F. et al., "The sense-city project," in [Vibrations,Shocks and Noise XVIII symposium,], (2012). 